\title{
STUDY ON MCNP6 MODEL IN THE CALCULATION OF KINETIC PARAMETERS FOR PEBBLE BED REACTOR
}

\author{
Zuhair $^{a, *}$, SUWoto $^{a}$, Topan Setiadipura $^{a}, \mathrm{ZAKI} \mathrm{SU}^{\prime} \mathrm{UD}^{b}$ \\ ${ }^{a}$ Center for Nuclear Reactor Technology and Safety - BATAN, Puspiptek Area, Office Building No. 80, Serpong, \\ 15310 Tangerang Selatan, Indonesia \\ ${ }^{b}$ Bandung Institute of Technology (ITB), Physics Department, Nuclear Physics and Biophysics Research Group, \\ Jl. Ganesha 10, 40132 Bandung, Indonesia \\ * corresponding author: zuhair@batan.go.id
}

\begin{abstract}
When conducting a nuclear reactor transient analysis, the most important parameter, called the kinetic parameter, is required. The calculation of kinetic parameters can be conducted using several methods. The deterministic method is one possible method that relies on the forward and adjoint neutron fluxes to provide the kinetic parameters calculation based on the perturbation theory. In this study, the Monte Carlo transport code MCNP6 was utilized to perform the exact prediction of the kinetic parameters of a pebble bed reactor. The core was modelled with a different fuel composition of uranium loading per pebble, ${ }^{235} \mathrm{U}$ enrichment and $\mathrm{H} / \mathrm{D}$ ratio. It was found that keff strongly depends on the uranium loading, uranium enrichment and $\mathrm{H} / \mathrm{D}$ ratio while the $\beta_{\text {eff }}$ dependence is insignificant. The increase in the prompt neutron lifetime $(\ell)$ and mean generation time $(\Lambda)$ as a function of $\mathrm{H} / \mathrm{D}$ ratio are insignificant as compared to the decrease of those parameters in the case of uranium loading or uranium enrichment. These results conclude that the selection of uranium loading per pebble, ${ }^{235} \mathrm{U}$ enrichment and $\mathrm{H} / \mathrm{D}$ ratio should be considered carefully for the control and inherent safety performances.
\end{abstract}

KEYWORDS: kinetic parameters, pebble bed reactor, uranium loading, ${ }^{235} \mathrm{U}$ enrichment, H/D ratio.

\section{INTRODUCTION}

World energy demand is expected to continuously increase in the next decades. According to the International Energy Agency (IEA), in 2035, the world energy demand will increase by a third, but the public objection on nuclear energy, which is mainly due to the age of the long waste and the possibility of an accident like Fukushima in Japan in 2011 or Chernobyl in the Soviet Union in 1986, became a special problem requiring a crucial attention. To overcome this problem effectively and also to accommodate the increasing demand of sustainable world energy supply, thirteen states and institutions, which pursue the field of nuclear technology and energy established a Generation IV International Forum (GIF). This forum set a focus on the foundation for a next generation nuclear energy system, which surpasses the current design in terms of sustainability, non-proliferation, resource utilization, safety and waste management [1, 2].

Nowadays, the attention of nuclear reactor physicists on the high-temperature reactor (HTR) increases significantly because of its inherent safety concept that can ensure that the core remains intact in any accident scenarios and radioactive fission products will not be released into the environment. In the inherent safety concept, the reactor naturally responds to the errors or malfunctions without being stimulated by an active system so that it does not reach a dangerous condition. The release of fission products into the en- vironment is protected by coated fuel particles, which are resistant to temperature and corrosion and are mechanically protected by graphite fuel elements. If all active control fails, the reactor can save itself and it does not require a human action mechanism 3 .

The pebble bed reactor is a type of the HTR, which is grouped as one of the Generation IV nuclear reactor system using graphite as a neutron moderator and helium as a coolant. Various advantages of the pebble bed reactor, such as high thermal conductivity, inert cooling, inherent safety, the retention capabilities of fission products, proliferation resistance and online fuel loading without periods of reactor shutdown and control of excess reactivity, complement the consideration of the pebble bed reactor as a promising candidate for next-generation commercial nuclear power plants [4].

A transient analysis is very important to represent the reactor performance during dynamic changes, such as in temperature, control rod positions, coolant flow rate, along its operation, malfunction, or even accident condition. When conducting a nuclear reactor transient analysis, the most notable parameter, called the kinetic parameter, is required. The kinetic parameters consist of the delayed neutron fraction, prompt neutron lifetime, mean generation time, and half-lives. The delayed neutron fraction is defined as a ratio of the number of neutrons that are delayed to the total fission neutrons. Fission neutrons are the neutrons produced from fission reactions consisting of 
prompt and delayed neutrons. A prompt neutron is a neutron emitted immediately from fission reactions while a delayed neutron is a neutron emitted from fission products decay at any time scale of several milliseconds (ms) [5, 6]. Although the delayed neutrons are only a very small fraction of the total number of neutron generated from the fission reaction, they play a dominant role in the control of the fission chain reaction. Therefore, the accurate calculation of the kinetic parameters is the main requirement in the field of reactor physics [7].

The calculation of kinetic parameters can be conducted using several methods. The aforementioned deterministic method relies on the forward and adjoint neutron fluxes to provide the kinetic parameters calculation based on the perturbation theory. The method is usually used in $2-\mathrm{D}$ or 3 -D reactor geometry and multigroup neutron energy approximation. Monte Carlo is another method that uses probabilistic neutron interaction. This method usually calculates the kinetic parameters based on the comparison of multiplication factors with both prompt and delayed neutrons and with a prompt neutron only. In this study, the Monte Carlo transport code MCNP6 [8] was utilized to perform the exact prediction of the kinetic parameters of a pebble bed reactor, such as effective delayed neutrons fraction $\left(\beta_{\text {eff }}\right)$, prompt neutron lifetime $(\ell)$ and mean generation time $(\Lambda)$. While other Monte Carlo methods require two criticality calculations to obtain the kinetic parameters, The MCNP6 can perform both calculations simultaneously. The pebble bed core configuration including the graphite reflector and other reactor geometry, such as carbon layer around the system, helium channels, control rods were modelled in detail and comprehensively. The purpose of this paper is to describe the MCNP6 model and to investigate the effects of changing the kinetic parameters, such as uranium loading, ${ }^{235} \mathrm{U}$ enrichment and $\mathrm{H} / \mathrm{D}$ ratio represented core size of the pebble bed reactor. These three parameters are important parameters, which dictate the neutronic design of a pebble bed reactor [9]. The investigation of these design parameters is the novelty of the current study. The reactor geometry based on the HTR-Modul [10] was selected as the reactor model. The continuous energy nuclear data library ENDF/B-VII [1] was applied to complete the calculation analysis.

\section{DesCRIPTION OF PEBBLE BED REACTOR}

The pebble bed reactor chosen as the reactor model in this study is a close approximation based on the HTRModul. HTR-Modul design has been extensively used as a reference model for the Pebble Bed Modular Reactor (PBMR) South African [12] and Chinese HTR programs [13. The reactor core contains 359,548 randomly distributed fuel pebbles. The packing fraction restricts the core, which is occupied by fuel pebbles with a volume fraction of $61 \%$. The power density is set at $3 \mathrm{MW} / \mathrm{m}^{3}$ and the thermal power at $200 \mathrm{MW}$.

The shape of the core is cylindrical with a dimension of $300 \mathrm{~cm}$ in diameter and $943 \mathrm{~cm}$ in height. It is surrounded by reflectors made of graphite containing channels for insertion of control rods and helium flow. This core size is specified by the assumed power and by imposing an H/D ratio of 3.14 to minimize the probability of neutron leakage. The graphite is a primary material in the core structure and acts as a neutron moderator. Helium has excellent heat transfer properties as a coolant. It does not react chemically with the fuel elements and remains less radioactive because only a few neutrons are absorbed. In the pebble bed reactor, the cooling helium enters the core and flows through spaces in the pebble packing with the temperature of $250^{\circ} \mathrm{C}$ and is heated up to $750{ }^{\circ} \mathrm{C}$.

The unique feature of the pebble bed reactor is the online refuelling capability in which the fuel pebbles are inserted during operation. The pebble can be recirculated into the core after checking the integrity and fuel burnup performed. The fuel pebble is designed to pass through the reactor several times before being discharged as used fuel to be stored in fuel storage for further reprocessing. The parameter and core specification of the pebble bed reactor are given in Table 1 .

The fuel pebble has a diameter of $6 \mathrm{~cm}$ consisting of 11,600 TRISO particles randomly distributed in the inner graphite matrix with a radius of $2.5 \mathrm{~cm}$ and outer graphite shell with a thickness of $0.5 \mathrm{~cm}$. The uranium content of the fuel pebble is $7 \mathrm{~g}$. The TRISO particle contains a $7.8 \%$ enriched $\mathrm{UO}_{2}$ kernel surrounded by coating layers of porous carbon buffer, inner pyrolytic carbon (iPyC), silicon carbide $(\mathrm{SiC})$ and outer pyrolytic carbon (oPyC) with a thickness of $90,40,35$ and $35 \mu \mathrm{m}$, respectively.

The TRISO coating materials and densities are the standard value commonly used in the typical pebble bed reactor. The coating layers are designed as multiple defences and barriers of releasing fission products from the fuel pebble by an inherent restriction of fuel temperature to less than $1600{ }^{\circ} \mathrm{C}$ in any accident conditions. The overall diameter of the coated particle is $0.090 \mathrm{~cm}$. The schematic view of the pebble bed reactor and fuel pebble geometry are illustrated in Figure 1 and 2 respectively. The specification of the fuel pebble and TRISO coated particle is given in Table 2 .

\section{Calculation model}

The pebble bed reactor is a high-temperature gas cooled reactor, which has unique core physics characteristics and neutron performance that differs from common reactors such as light water reactors (LWRs). This uniqueness is one of the advantages of pebble bed reactors but these advantages cause a difficulty in modelling the reactor. and thus requires special techniques. Many traditional methods are able to model a 


\begin{tabular}{lc}
\hline Reactor parameter & \\
\hline Thermal power $(\mathrm{MW})$ & 200 \\
Helium inlet/outlet temperatures $\left({ }^{\circ} \mathrm{C}\right)$ & $250 / 750$ \\
Helium pressure $(\mathrm{MPa})$ & 6 \\
Helium mass flow rate $(\mathrm{kg} / \mathrm{s})$ & 85 \\
Helium coolant density $\left(\mathrm{g} / \mathrm{cm}^{3}\right)$ & $4.33 \times 10^{-3}$ \\
\hline Core specification & \\
\hline Core power density $\left(\mathrm{MW} / \mathrm{m}^{3}\right)$ & 3 \\
Diameter $(\mathrm{cm}) /$ height $(\mathrm{cm})$ & $300 / 943$ \\
Number of fuel pebble per $\mathrm{m}^{3}$ & 3594 \\
Number of fuel pebble in core & 0.548 \\
Pebble packing fraction in core & \\
\hline
\end{tabular}

TABlE 1. Parameter and core specification of pebble bed reactor 10.

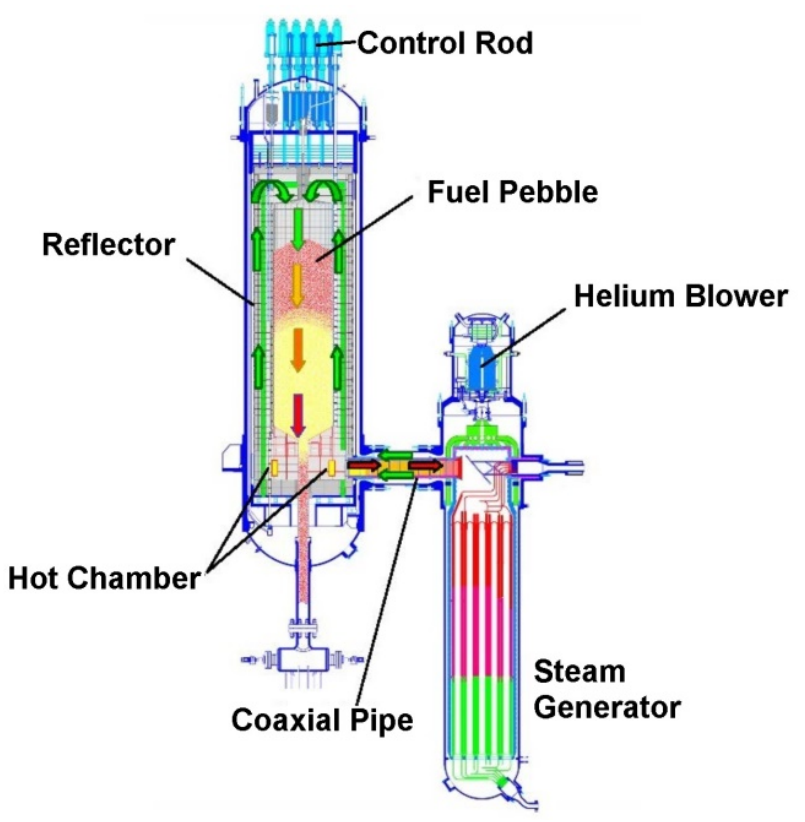

Figure 1. The schematic view of pebble bed reactor [14].

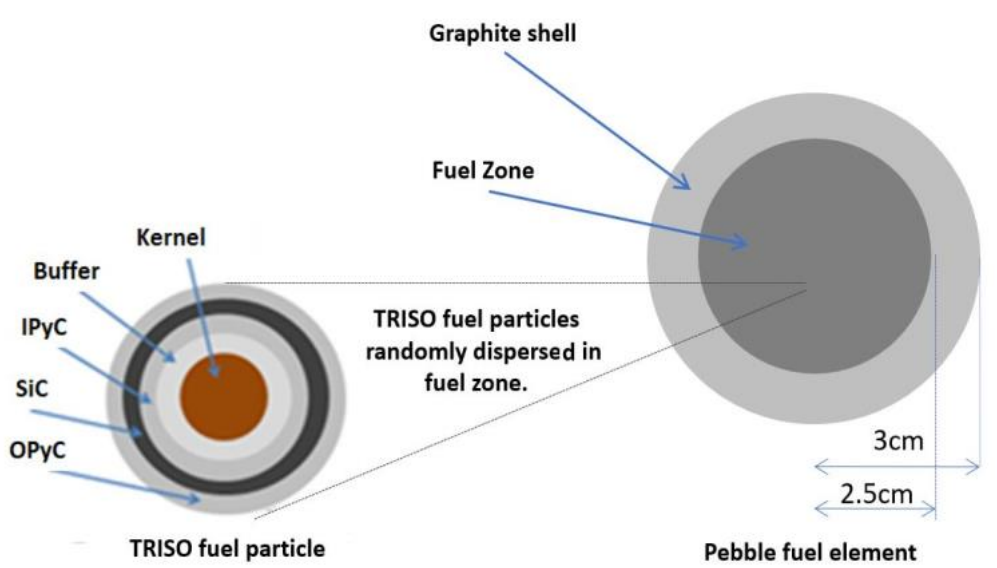

Figure 2. The schematic view of fuel pebble geometry 9 . 


\begin{tabular}{lc}
\hline Fuel pebble & \\
\hline Diameter of pebble $(\mathrm{cm})$ & 6 \\
Diameter of fueled zone $(\mathrm{cm})$ & 5 \\
Thickness of graphite shell $(\mathrm{cm})$ & 0.5 \\
Density of graphite shell $\left(\mathrm{g} / \mathrm{cm}^{3}\right)$ & 1.75 \\
Natural boron impurity in graphite shell $(\mathrm{ppm})$ & 0.6 \\
Density of graphite matrix $\left(\mathrm{g} / \mathrm{cm}^{3}\right)$ & 1.75 \\
Natural boron impurity in graphite matrix $(\mathrm{ppm})$ & 0.6 \\
\hline TRISO coated particle & \\
\hline Diameter of kernel $(\mu \mathrm{m})$ & 500 \\
Density of kernel $\left(\mathrm{g} / \mathrm{cm}^{3}\right)$ & 10.4 \\
\hline Coating layers & \\
\hline Material & $\mathrm{C} / \mathrm{iPyC} / \mathrm{SiC} / \mathrm{oPyC}$ \\
Thickness $(\mu \mathrm{m})$ & $90 / 40 / 35 / 35$ \\
Density of coating $\left(\mathrm{g} / \mathrm{cm}^{3}\right)$ & $1.04 / 1.88 / 3.15 / 1.88$ \\
\hline
\end{tabular}

TABLE 2. Specification of fuel pebble and TRISO coated particle [10].

conventional nuclear reactor. However, they cannot be applied to model the high temperature reactor because it cannot treat double heterogeneity effects. Therefore, the development of a computer simulation to construct the double heterogeneous model of the hightemperature reactor is highly required. The MCNP6 is a Monte Carlo transport code that can address these needs appropriately. With the stochastic nature and capability of handling complex geometries, the MCNP6 can accurately represent the double heterogeneity of a pebble bed reactor consisting of TRISO coated fuel particles embedded in graphite matrix (first heterogeneity) and fuel pebbles distributed in the core region (second heterogeneity).

In the first heterogeneity, the TRISO particle arrangement was modelled explicitly as a simple cubic (SC) lattice. A lattice pitch was calculated by considering the dimension of the TRISO particle and its packing fraction. The model was based on precise descriptions of the fuel kernel with their coatings and graphite matrix outside the TRISO particle. A large number of TRISO fuel particles in a pebble makes the fuel pebble modelled by constructing the repeated structure on the SC lattice of the TRISO particle in the graphite matrix throughout the volume of the pebble fuelled zone. The pitch size $\left(p_{S C}\right)$ of the TRISO lattice was obtained using the following formula:

$$
p_{S C}=r_{T} \cdot \sqrt[3]{\frac{4 \pi}{3 f_{t}}}
$$

where $r_{T}$ is TRISO radius, $f_{T}$ is packing fraction of TRISO particle.

A $0.5 \mathrm{~cm}$ graphite shell thickness covering the fuel zone was modelled to complete the fuel pebble model. The radius of the fuel pebble is $3 \mathrm{~cm}$, while the number of TRISO particles and its geometrical size may vary depending on the reactor type and fuel cycle scenario. The repeated structure capability provided in the

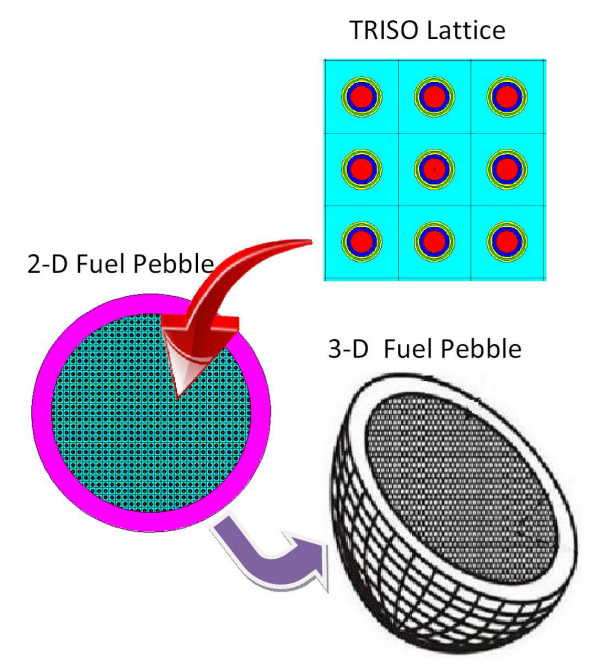

Figure 3. MCNP6 model for first heterogeneity of pebble bed reactor [15].

MCNP6 is required for treating the randomness problem of modelling a high temperature reactor. Figure 3 illustrates the MCNP6 model for first heterogeneity of a pebble bed reactor. The nuclide concentration of TRISO particles in the fuel pebble with ${ }^{235} \mathrm{U}$ enrichment of $7.8 \%$ is given in Table 3 while the nuclide concentrations of the graphite matrix and graphite shell are given in Table 4 .

In the second heterogeneity, the fuel pebble distribution in the reactor core was modelled explicitly as a body-centred cubic (BCC) lattice with a pitch obtained from a relation of pebble radius and packing fraction. Like a fuel pebble, a large number of pebbles in the core making the repeated structure was utilized to construct the core model containing $\sim 360,000$ fuel pebbles. The use of the repeated structure feature brings out the clipped particles in the fuelled zone surface of the fuel pebbles and the clipped fuel pebbles in 


\begin{tabular}{|c|c|c|c|}
\hline \multicolumn{4}{|c|}{ Fuel kernel } \\
\hline${ }^{234} \mathrm{U}$ & $1.36692 \cdot 10^{-5}$ & ${ }^{238} \mathrm{U}$ & $2.13499 \cdot 10^{-2}$ \\
\hline${ }^{235} \mathrm{U}$ & $1.83043 \cdot 10^{-3}$ & ${ }^{16} \mathrm{O}$ & $4.63880 \cdot 10^{-2}$ \\
\hline \multicolumn{4}{|c|}{ Coating layers } \\
\hline \multicolumn{2}{|c|}{ Porous carbon buffer } & \multicolumn{2}{|c|}{$\mathrm{iPyC} / \mathrm{oPyC}$} \\
\hline${ }^{12} \mathrm{C}$ & $5.20600 \cdot 10^{-2}$ & ${ }^{12} \mathrm{C}$ & $9.42000 \cdot 10^{-2}$ \\
\hline \multicolumn{4}{|l|}{$\mathrm{SiC}$} \\
\hline${ }^{12} \mathrm{C}$ & $4.72300 \cdot 10^{-2}$ & ${ }^{29} \mathrm{Si}$ & $2.20564 \cdot 10^{-3}$ \\
\hline${ }^{28} \mathrm{Si}$ & $4.35602 \cdot 10^{-2}$ & ${ }^{30} \mathrm{Si}$ & $1.46413 \cdot 10^{-3}$ \\
\hline
\end{tabular}

TABLE 3. Nuclide concentration of TRISO particle (atoms/barn-cm) 10].

\begin{tabular}{rrrr}
\hline & Graphite matrix & & Graphite shell \\
\hline${ }^{12} \mathrm{C}$ & $8.77414 \cdot 10^{-2}$ & ${ }^{12} \mathrm{C}$ & $8.77414 \cdot 10^{-2}$ \\
${ }^{10} \mathrm{~B}$ & $1.92995 \cdot 10^{-8}$ & ${ }^{10} \mathrm{~B}$ & $1.92995 \cdot 10^{-8}$ \\
${ }^{11} \mathrm{~B}$ & $7.81729 \cdot 10^{-8}$ & ${ }^{11} \mathrm{~B}$ & $7.81729 \cdot 10^{-8}$ \\
\hline
\end{tabular}

TABLE 4. Nuclide concentrations of graphite matrix and graphite shell (atoms/barn-cm) [10.

the reactor core wall surface. The pitch size (pBCC) of the fuel pebble lattice was determined based on the following formula:

$$
p_{B C C}=r_{p} \cdot \sqrt[3]{\frac{8 \pi}{3 f_{p}}}
$$

where $r_{P}$ is pebble radius, $f_{P}$ is packing fraction of fuel pebble.

The reduction of the packing fraction is one of the methods that can eliminate the clipped particles and clipped fuel pebbles in the surface. Therefore, the packing fraction of the pebble was reduced from $61 \%$ to $59.78 \%$, except for the packing fraction of the particle since it has been proven that it gives an insignificant impact on the results. The graphite reflector and other reactor geometry, such as carbon layer around the system, helium channels and control rods, were modelled in detail and comprehensively. The modelling procedure in this study was first developed by Lebenhaft [16] and utilized in some publications [17] 30. Figure 4 illustrates the MCNP6 model for the second heterogeneity of the pebble bed reactor.

\section{Results AND Discussion}

In this study, the analysed kinetic parameters are effective delayed neutrons fraction $\left(\beta_{e f f}\right)$, prompt neutron lifetime $(\ell)$ and mean generation time $(\Lambda)$. The effective multiplication factor $\left(k_{e f f}\right)$ was also analysed due to the calculation of kinetic parameters being strongly connected with the criticality calculations. The KCODE card is required for running a reactor criticality problem. The KCODE consists of some information, such as the nominal number of source histories per $k_{e f f}$ cycle, an initial guess of $k_{e f f}$, the number of source cycles to skip before $k_{e f f}$ accumulation, and the total number of cycles in the problem.

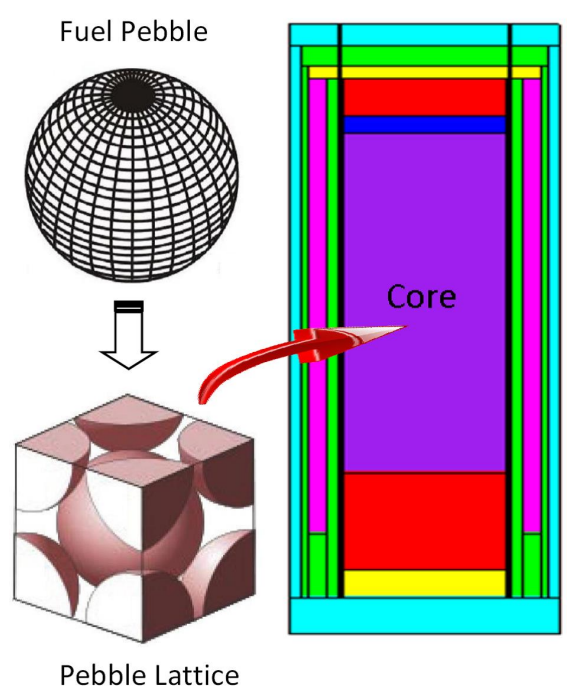

FIGURE 4. MCNP6 model for second heterogeneity of pebble bed reactor [15].

The KSRC card is the initial spatial distribution of fission neutrons. In this study, the location of the initial spatial distribution of the fission point was defined at the central of the fuel kernel and 10,000 particles per neutron life cycle were simulated. A total of 30 million neutron histories were used with discarding the first 125 of 750 cycles before averaging $k_{e f f}$ or accumulating the tallies.

The core has been modelled with a different fuel composition of uranium loading per pebble, ${ }^{235} \mathrm{U}$ enrichment and $\mathrm{H} / \mathrm{D}$ ratio to examine their effects on the kinetic parameters of a pebble bed reactor. The calculation of kinetic parameters was conducted by activating the KOPTS card in the MCNP6 input data. The KOPTS card is one of criticality calculation option provided in the MCNP6 to generate the 


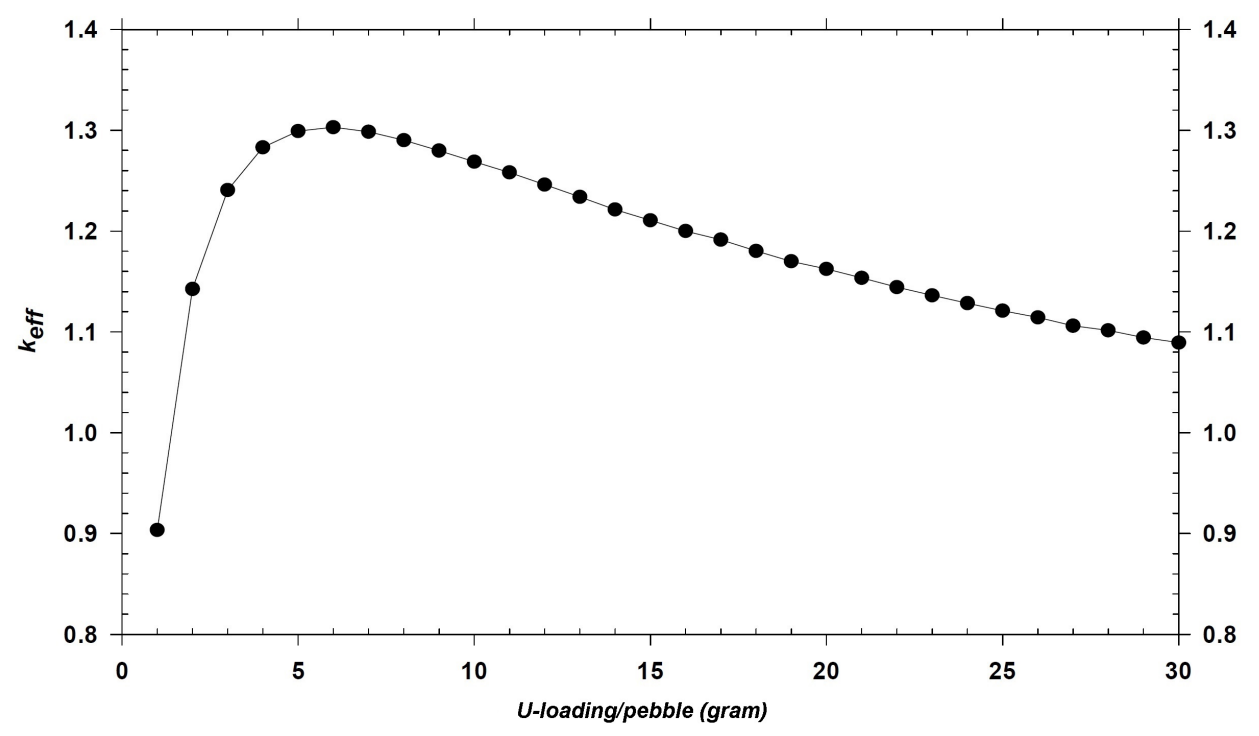

FiguRE 5 . The $k_{e f f}$ as a function of uranium loading.

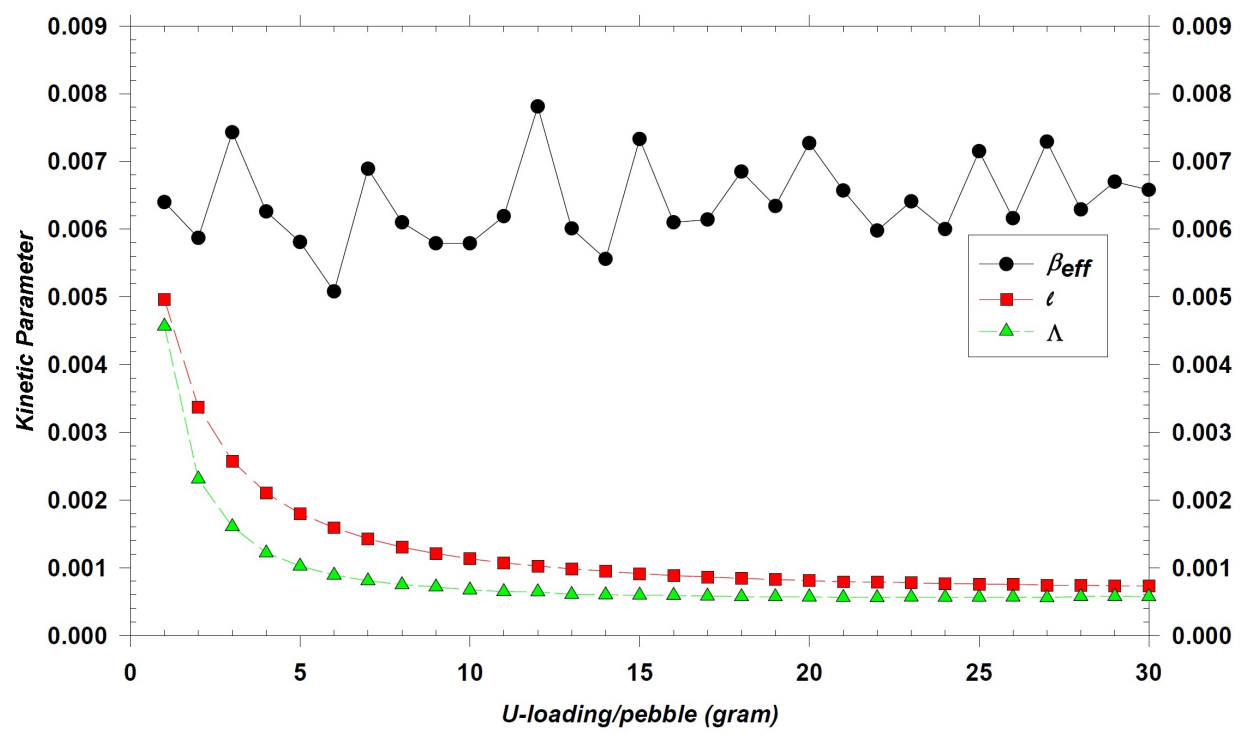

FIgURE 6 . The kinetic parameters as a function of uranium loading.

point-kinetics parameters, such as the neutron generation, the effective delayed neutron fraction and so on. The control rods were positioned at fully withdrawn and the reactor core volume was completely filled with $\sim 360,000$ fuel pebbles in all calculations.

Figures 5 and 6 show the calculation results as a function of uranium loading per pebble. The uranium loading varying from 1 gram to 30 grams per pebble corresponds to the decrease of the lattice pitch from 0.33989 to $0.10939 \mathrm{~cm}$. The pebble containing up to $30 \mathrm{~g}$ of uranium has been developed, but a restriction to $20 \mathrm{~g}$ should be considered as a limit, because the coated fuel particles will be damaged during the fabrication process. In this model, the core dimensions were set to $300 \mathrm{~cm}$ in diameter and $943 \mathrm{~cm}$ in height. The ${ }^{235} \mathrm{U}$ enrichment of $7.8 \%$ was chosen to match the HTR-Modul design.
From Figure 5 it is found that the effective multiplication factor $\left(k_{e f f}\right)$ strongly depends on the considered uranium loading. This figure shows that $1 \mathrm{~g}$ uranium per pebble produces the smallest $k_{\text {eff }}$ value of $0.90302 \pm 0.00011$, the curve increases sharply and reaches a maximum value of $1.30314 \pm 0.00015$ at $6 \mathrm{~g}$ uranium per pebble then decreases slowly up to $30 \mathrm{~g}$ uranium per pebble. The $k_{\text {eff }}$ at this mass is $1.08953 \pm 0.00016$. The $k_{e f f}$ curve gives the impression that the neutron moderation effect is behind this tendency. For low uranium mass, the presence of graphite is very abundant in the fuel pebble. When the number of graphite is larger than the number of uranium in $\mathrm{UO}_{2}$, then it can moderate the core optimally, which leads to the maximum reactor criticality. On the contrary, the increase of uranium mass causes lesser amount of graphite. As a result, the neutron moderation decreases and the reactor multiplication 


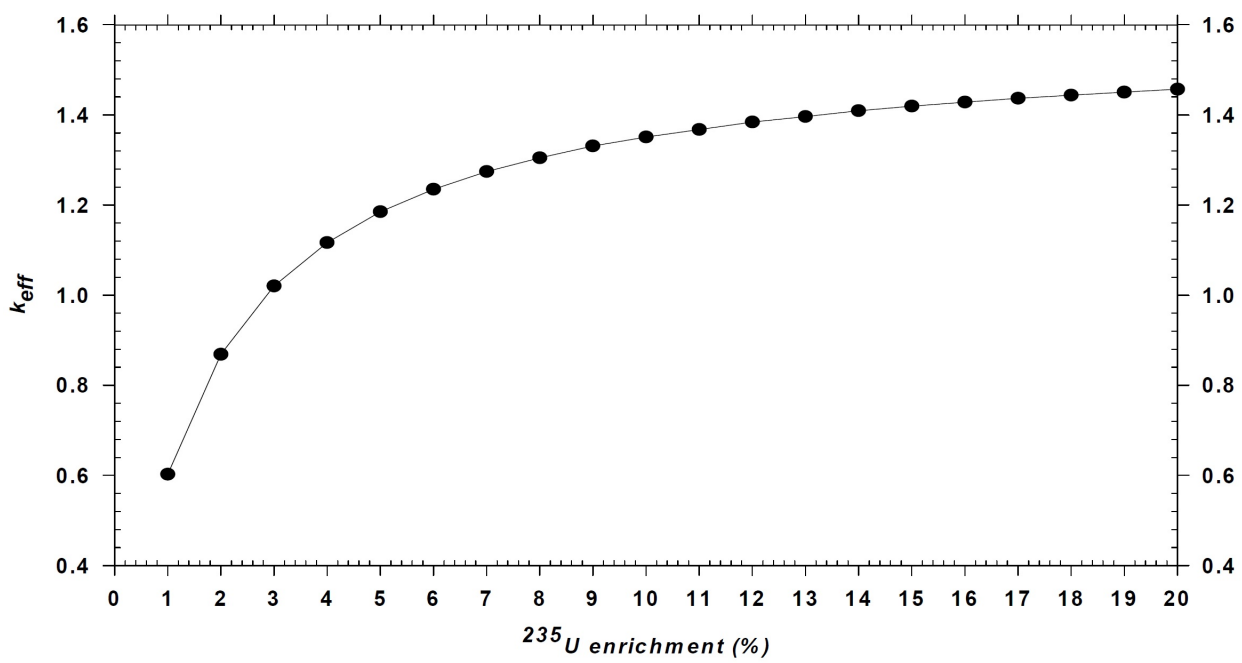

Figure 7 . The $k_{\text {eff }}$ as a function of uranium enrichment.

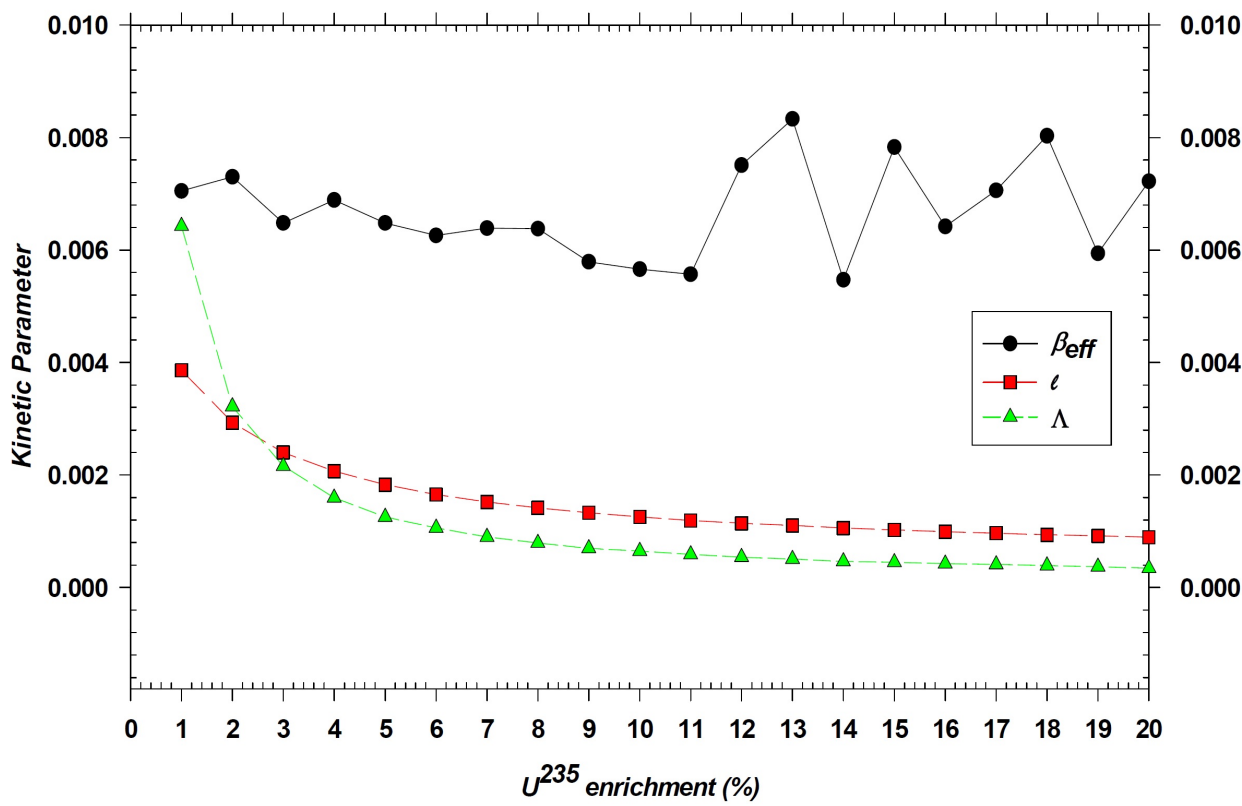

FIGURE 8. The kinetic parameters as a function of uranium enrichment.

factor will be reduced. Therefore, the pebble containing approximately $4-10 \mathrm{~g}$ of uranium was chosen as preferable in the pebble bed reactor design.

Figure 6 expresses the insignificant dependency of $\beta_{\text {eff }}$ on the uranium loading. The reason for this situation is predicted due to the cores with different uranium loading per pebble having the same size. The $\beta_{\text {eff }}$ value fluctuates between $0.00618 \pm 0.00036$ and $0.00716 \pm 0.00023$, and its average is $0.00667 \pm 0.00028$. It can be seen that, if the uranium loading increases, the prompt neutron lifetime $(\ell)$ and mean generation time $(\Lambda)$ will exponentially decrease. This is due to the neutron spectrum hardening by the decrease in the uranium loading. Reducing the prompt neutron lifetime $(\ell)$ from $1 \mathrm{~g}$ to $30 \mathrm{~g}$ uranium per pebble is very significant, it decreases from $4.9606 \mathrm{e}^{-3} \pm 0.0008 \mathrm{e}^{-3} \mathrm{~s}$ to $7.3803 \mathrm{e}^{-4} \pm 0.0037 \mathrm{e}^{-4} \mathrm{~s}$, by 6.7 -times. The neutron generation time $(\Lambda)$ decreases from $4.5875 \mathrm{e}^{-3} \pm$
$0.0102 \mathrm{e}^{-3} \mathrm{~s}$ to $5.8221 \mathrm{e}^{-4} \pm 0.0317 \mathrm{e}^{-4} \mathrm{~s}$. These shorter parameters limit the inherent safety of the reactor.

The results as a function of uranium enrichment are illustrated in Figures 7 and 8 . The uranium enrichment, which varies from $1 \%$ to $20 \%$ conforms to the adding of ${ }^{235} \mathrm{U}$ content in the fuel kernel. The enrichment is maintained below $20 \%$ to comply with the non-proliferation treaty. In this model, the core dimension was also set to $300 \mathrm{~cm}$ in diameter and $943 \mathrm{~cm}$ in height. The mass of uranium per pebble was specified to $7 \mathrm{~g}$. Figure 7 shows the increase of the $k_{\text {eff }}$ as a function of ${ }^{235} \mathrm{U}$ enrichment. This trend is derived from the fission chain reactions that occur due to the interaction between neutrons and fissile isotopes of ${ }^{235} \mathrm{U}$. The higher the enrichment, the more ${ }^{235} \mathrm{U}$ isotope interacts with neutrons. The increasing fission reactions cause the increasing reactor multiplication factor. 


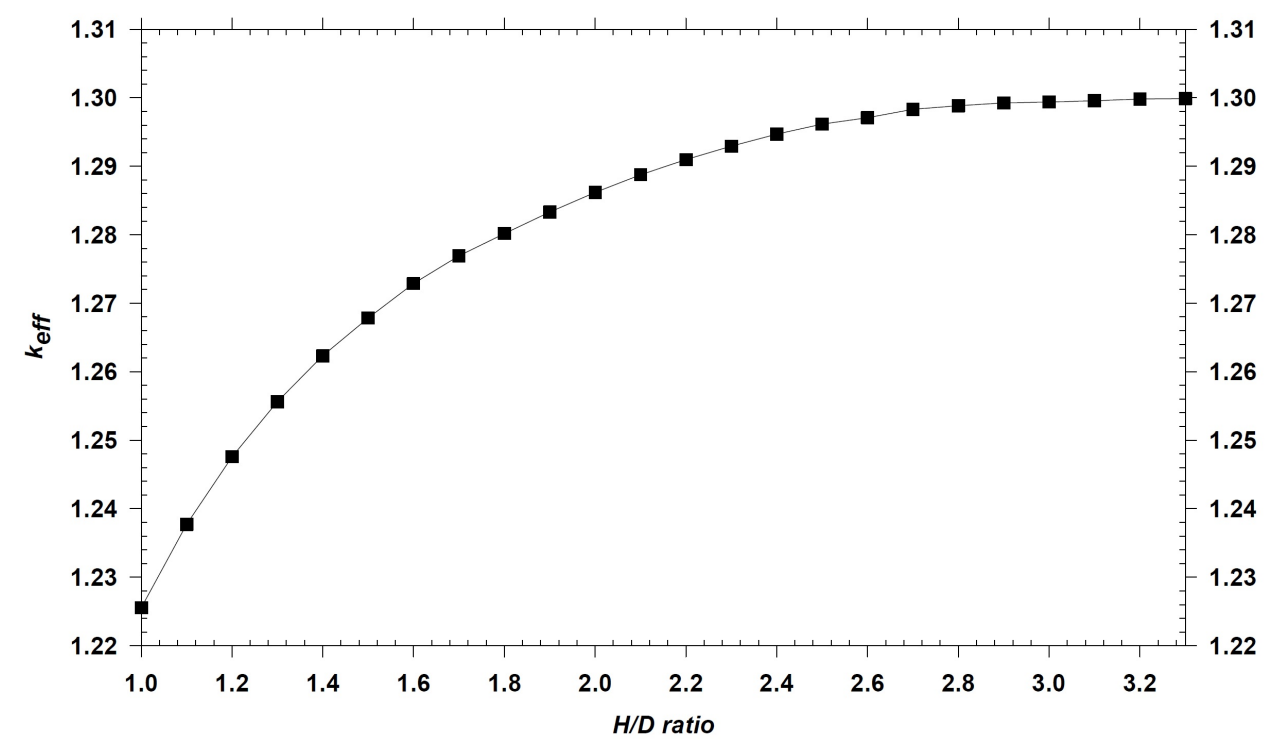

Figure 9. The $k_{\text {eff }}$ as a function of $\mathrm{H} / \mathrm{D}$ ratio.

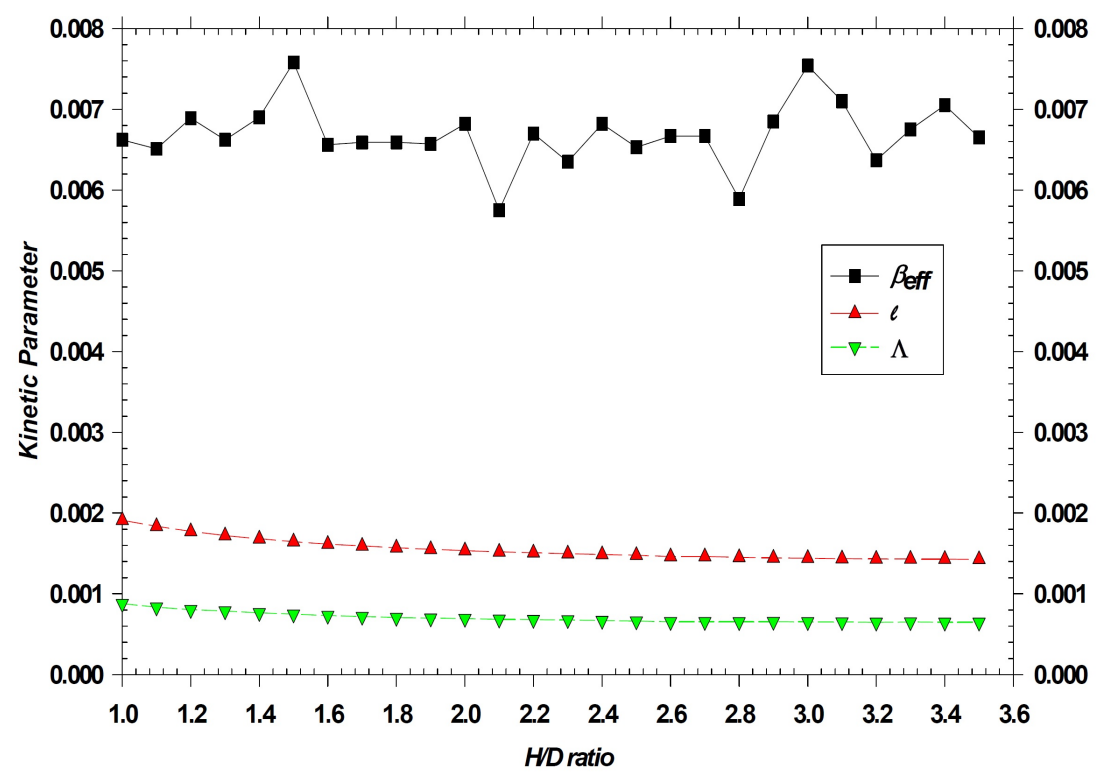

Figure 10. The kinetic parameters as a function of H/D ratio.

Figure 8 reflects the insignificant uranium enrichment dependence on $\beta_{\text {eff }}$. The average of $\beta_{\text {eff }}$ is $0.00654 \pm 0.00050$. This phenomenon is due to the cores with different fuel enrichment having the same size such as in the case of uranium loading per pebble. It can also be observed that there is a decreased prompt dependency of neutron lifetime $(\ell)$ and mean generation time $(\Lambda)$ as a function of ${ }^{235} U$ enrichment, namely, from $3.8610 \mathrm{e}^{-3} \pm 0.0006 \mathrm{e}^{-3} \mathrm{~s}$ to $8.9995 \mathrm{e}^{-4} \pm 0.0035 \mathrm{e}^{-4} \mathrm{~s}$ and from $6.2219 \mathrm{e}^{-3} \pm$ $0.0170 \mathrm{e}^{-3} \mathrm{~s}$ to $1.6189 \mathrm{e}^{-4} \pm 0.0163 \mathrm{e}^{-4} \mathrm{~s}$, respectively. The high ${ }^{235} U$ enrichment tends to produce a neutron spectrum which shifts to fast range and consequently results in shorter prompt neutron lifetime $(\ell)$ and mean generation time $(\Lambda)$. The reactor will be difficult to control if these parameters are getting low.
The results as a function of $\mathrm{H} / \mathrm{D}$ ratio are illustrated in Figures 9 and 10. The core model was prepared with different $H / D$ ratios, from 1 to 3.5 . The value 3.5 as the highest $\mathrm{H} / \mathrm{D}$ ratio was chosen because it included the height of the HTR-Modul. The diameter was maintained to $3 \mathrm{~m}$ and the height was adjusted by the $\mathrm{H} / \mathrm{D}$ ratio considered. The calculation was performed with ${ }^{235} \mathrm{U}$ enrichment of $7.8 \%$ and uranium loading of $9 \mathrm{~g}$ per pebble. Figure 9 shows that the $k_{\text {eff }}$ increases from $1.22554 \pm 0.00017$ to $1.29987 \pm 0.00015$ as the $\mathrm{H} / \mathrm{D}$ ratio gets larger. It is known that the greater the $\mathrm{H} / \mathrm{D}$, the larger the core volume. Consequently, the amount of fuel pebble is also increased, and therefore increasing the reactor multiplication factor.

Figure 10 confirms that there is an insignificant dependency of $\beta_{\text {eff }}$ on the $\mathrm{H} / \mathrm{D}$ ratio even though the core size is different. The $\beta_{\text {eff }}$ value fluctuates 
between $0.00575 \pm 0.00027$ and $0.00758 \pm 0.00053$, its average is $0.00669 \pm 0.00040$. Looking again at Figure 9 as expected, the high $\mathrm{H} / \mathrm{D}$ ratio will produce a harder neutron spectrum, therefore, the prompt neutron lifetime $(\ell)$ and mean generation time $(\Lambda)$ become short. However, the decrease in the prompt neutron lifetime $(\ell)$ from $1.9113 \mathrm{e}^{-3} \pm 0.00057 \mathrm{e}^{-3} \mathrm{~s}$ to $1.4272 \mathrm{e}^{-3} \pm 0.00042 \mathrm{e}^{-3} \mathrm{~s}$ and mean generation time $(\Lambda)$ from $8.7851 \mathrm{e}^{-4} \pm 0.0372 \mathrm{e}^{-4} \mathrm{~s}$ to $6.4773 \mathrm{e}^{-4} \pm$ $0.0375 \mathrm{e}^{-4} \mathrm{~s}$ are only about 1.3 times shorter. These are insignificant as compared to the decrease of those parameters as a function of the uranium loading or uranium enrichment.

\section{CONClusion}

A study on the MCNP6 model in the calculation of kinetic parameters of a pebble bed reactor has been conducted. The core was modelled with different fuel compositions of uranium loading per pebble, ${ }^{235} \mathrm{U}$ enrichment and the $\mathrm{H} / \mathrm{D}$ ratio. It was found that $k_{\text {eff }}$ strongly depends on the uranium loading, uranium enrichment and the $\mathrm{H} / \mathrm{D}$ ratio while the $\beta_{\text {eff }}$ dependence is insignificant. The decrease in the prompt neutron lifetime $(\ell)$ and mean generation time $(\Lambda)$ as a function of the $\mathrm{H} / \mathrm{D}$ ratio are insignificant as compared to the decrease of those parameters in the case of uranium loading or uranium enrichment. These results conclude that, in particular for a pebble bed reactor with a thermal power of $200 \mathrm{MW}$, the selection of uranium loading of $4-10 \mathrm{~g}$ per pebble, ${ }^{235} \mathrm{U}$ enrichment of $7-10 \%$ and $H / D$ ratio of less than 3.5 should be considered for an optimum reactor control performance.

\section{ACKNOWLEDGEMENTS}

We would like to express our sincere gratitude to Dr. Geni Rina Sunaryo for her continuous motivation and support in conducting this research. We would also like to thank Syaiful Bakhri, Ph.D. for his comments and corrections on our draft version, which lead to an improvement of this paper. This research work was funded by the Government of the Republic of Indonesia through DIPA PTKRN-BATAN FY 2020.

\section{REFERENCES}

[1] L. L. W. Frima. Burnup in a Molten Salt Fast Reactor. Master's thesis, Delft University of Technology, 2013.

[2] C. Graafland. Modeling and Analysis of a Depressurized Loss of Forced Cooling Event in a Thorium Fueled High Temperature Reactor. Bachelor thesis, Delft University of Technology, 2014.

[3] H. Ohashi, H. Sato, K. Kunitomi, M. Ogawa. Concept on inherent safety in high-temperature gas-cooled reactor. Transactions of the Atomic Energy Society of Japan 13:17 - 26, 2014. DOI:10.3327/taesj.J13.013

[4] R. Buman. Radiotoxicity and Decay Heat Comparison of Nuclear Waste Produced by a Thorium or Uranium Fuelled Pebble Bed Reactor. Bachelor thesis, Delft University of Technology, 2014.
[5] S. A. A. Alameri. Couple Nuclear Reactor Thermal Energy Storage System for Enhanced Load Following Operation. Ph.D. thesis, Colorado School of Mines, 2015.

[6] Y. Zhang. Transmutation of Am in Sodium Fast Reactors and Accelerator Driven Systems. Ph.D. thesis, KTH Royal Institute of Technology, 2012.

[7] S. Ghrayeb. Investigations of Thorium based Fuel to Improve Actinide Burning Rate in S-PRISM Reactor. Master's thesis, The Pennsylvania State University, 2008.

[8] J. T. Goorley, et al. Initial MCNP6 Release Overview - MCNP6 version 1.0. LA-UR-13-22934. Tech. rep., Los Alamos National Laboratory, 2013.

[9] T. Setiadipura, D. Irwanto, Z. Zuhair. Preliminary neutronic design of high burnup OTTO cycle pebble bed reactor. Atom Indonesia 41:7, 2015. DOI:10.17146/aij.2015.350

[10] G. Strydom, H. D. Gougar. Preliminary reactor physics assessment of the HTR module with $14 \%$ enriched UCO fuel. Nuclear Engineering and Design 256:304 - 321, 2013. DOI:10.1016/j.nucengdes.2012.08.013.

[11] M. Chadwick, P. Obložinský, M. Herman, et al. Endf/b-vii.0: Next generation evaluated nuclear data library for nuclear science and technology. Nuclear Data Sheets 107(12):2931 - 3060, 2006. DOI:10.1016/j.nds.2006.11.001.

[12] S. Thomas, T. Heyde. The development of PBMR reactors in South Africa: opportunities and risks. Transactions of the Royal Society of South Africa 56:116 - 124, 2001. DOI:10.1080/00359190109520509.

[13] Y. Xu, S. Hu, F. Li, S. Yu. High temperature reactor development in China. Progress in Nuclear Energy 47(1):260 - 270, 2005. DOI:10.1016/j.pnucene.2005.05.026

[14] Z. Dong. An artificial neural network compensated output feedback power-level control for modular high temperature gas-cooled reactors. Energies 7:1149 1170, 2014. DOI:10.3390/en7031149

[15] Z. Zuhair, S. Suwoto, T. Setiadipura, et al. Study on characteristic of temperature coefficient of reactivity for plutonium core of pebbled bed reactor. Journal of Physics: Conference Series 962:012058, 2018. DOI:10.1088/1742-6596/962/1/012058

[16] J. R. Labenhaft. MCNP $4 B$ modeling of pebble-bed reactors. Master's thesis, Massachusetts Institute of Technology, 2001.

[17] S. A. Hosseini, M. Athari Allaf. Effects of the wallpaper fuel design on the neutronic behavior of the HTR-10. Kerntechnik 81:627 - 633, 2016. DOI:10.3139/124.110564

[18] Suwoto, H. Adrial, A. Hamzah, et al. Neutron dose rate analysis on HTGR-10 reactor using Monte Carlo code. Journal of Physics: Conference Series 962:012029, 2018. DOI:10.1088/1742-6596/962/1/012029

[19] Zuhair, Suwoto, T. Setiadipura, J. C. Kuijper. The effects of fuel type on control rod reactivity of pebble-bed reactor. Nukleonika 64(4):131 - 138, 2019. 
[20] Zuhair, Suwoto, T. Setiadipura, J. Kuijper. Study on the characteristics of effective delayed neutron fraction ( $\beta$ eff) for pebble-bed reactor with plutonium fuel. Iranian Journal of Science and Technology, Transactions A: Science 2019. DOI:10.1007/s40995-019-00772-8

[21] S. A. Hosseini, M. Athari Allaf. Implementation and benchmarking of ENDFVII based library for PBM reactor analysis with MCNP4c. Progress in Nuclear Energy 60:27 - 30, 2012.

[22] Suwoto, H. Adrial, Zuhair. Analisis Kuat Sumber Neutron dan Perhitungan Laju Dosis Neutron Teras Awal RDE. Urania Jurnal Ilmiah Daur Bahan Bakar Nuklir 23(1):33 - 44, 2017. DOI:10.17146/urania.2017.23.1.3119

[23] Zuhair, Suwoto, T. Setiadipura, Z. Su'ud. The effects of applying silicon carbide coating on core reactivity of pebble-bed HTR in water ingress accident. Kerntechnik 82:92-97, 2017. DOI:10.3139/124.110628.

[24] Zuhair, Suwoto, H. Adrial, T. Setiadipura. Study on MOX core characteristics of experimental power reactor using MCNP6 code. Journal of Physics: Conference Series 1198(2):022031, 2019. DOI:10.1088/1742-6596/1198/2/022031.

[25] Suwoto, Zuhair. Analisis laju dosis neutron teras RGTT200K dengan MCNP5. Jurnal Sains dan Teknologi Nuklir Indonesia 17:107, 2016. DOI:10.17146/jstni.2016.17.2.2350.
[26] L. Wahid, T. Setiadipura, Zuhair, et al. Criticality and burnup study on different TRISO modelling of HTR pebble. Journal of Physics: Conference Series 1198(2):022078, 2019. DOI:10.1088/1742-6596/1198/2/022078

[27] Zuhair, Suwoto. Analisis efek kecelakaan water ingress terhadap reaktivitas doppler teras RGTT200K. Jurnal Teknologi Reaktor Nuklir TRI DASA MEGA 17(1):31 - 40, 2015. DOI:10.17146/tdm.2015.17.1.2238

[28] Zuhair, Suwoto, P. Yazid. Investigasi parameter bahan bakar pebble dalam perhitungan teras thorium RGTT200K. Jurnal Sains dan Teknologi Nuklir Indonesia 14(2):65 - 77, 2013.

[29] Suwoto, Zuhair. Analisis sensitivitas ketebalan reflektor grafit teras RGTT200K menggunakan perhitungan Monte Carlo. Jurnal Pengembangan Energi Nuklir 16(2):73 - 83, 2014.

[30] Zuhair, Suwoto, P. Supriatna. Studi model heksagonal MCNP5 dalam perhitungan benchmark fisika teras HTR10. Jurnal Matematika \& Sains 17(2):61 - 70, 2012. 